\title{
Intrapulmonary Solitary Fibrous Tumor of the Lung: A Rare Case Presentation
}

\author{
${ }^{1} \mathrm{~S}$ Parinita, ${ }^{2} \mathrm{KN}$ Mohan Rao, ${ }^{3}$ Vivek
}

\begin{abstract}
Localized fibrous tumors of the lung arise from the visceral pleura and are pedunculated. They also project into the pleural cavity. The tumor with an entirely pulmonary location is extremely rare. We present here a rare case of intrapulmonary localized fibrous tumor with review of the literature.
\end{abstract}

Keywords: Immunohistochemistry, Sphindle cell neoplasim, Solitory fibrous tumor.

How to cite this article: Parinita S, Rao KNM, Vivek. Intrapulmonary Solitary Fibrous Tumor of the Lung: A Rare Case Presentation. J Med Sci 2016;2(2):42-44.

\section{Source of support: Nil}

Conflict of interest: None

\section{INTRODUCTION}

Solitary fibrous tumor (SFT) is a rare neoplasm (2.8 cases / 1 lakh persons/year), which frequently arises from the pleura, especially the visceral pleura, but intrapulmonary SFT is extremely rare. They generally have an indolent course and are often an incidental finding on chest images. Here, we report a rare case of intrapulmonary localized fibrous tumor.

\section{CASE REPORT}

A 50-year-old female, housewife, presented with generalized dull aching pain in the left chest, associated with breathlessness [Modified Medical Research Council (MMRC) - grade III] of 3 months duration. Patient had no significant past history. Routine blood investigations were within the normal limits. Chest X-ray showed a homogenous opacity occupying the left mid and lower zones (Fig. 1). A computed tomography (CT) scan of the chest confirmed the presence of a large nonenhancing heterogeneous solid mass lesion measuring $(11.2 \times 7.8 \times 12 \mathrm{~cm})$ in the left lower lobe with no evidence of lymphadenopathy (Figs 2 and 3). Ultrasonography (USG)-guided

\footnotetext{
${ }_{1,3}$ Postgraduate Student, ${ }^{2}$ Professor and Head

${ }^{1-3}$ Department of Chest Medicine, RajaRajeswari Medical College and Hospital, Bengaluru, Karnataka, India

Corresponding Author: S Parinita, Postgraduate Student Department of Chest Medicine, RajaRajeswari Medical College and Hospital, Bengaluru, Karnataka, India, e-mail: drparinita. md6@gmail.com
}

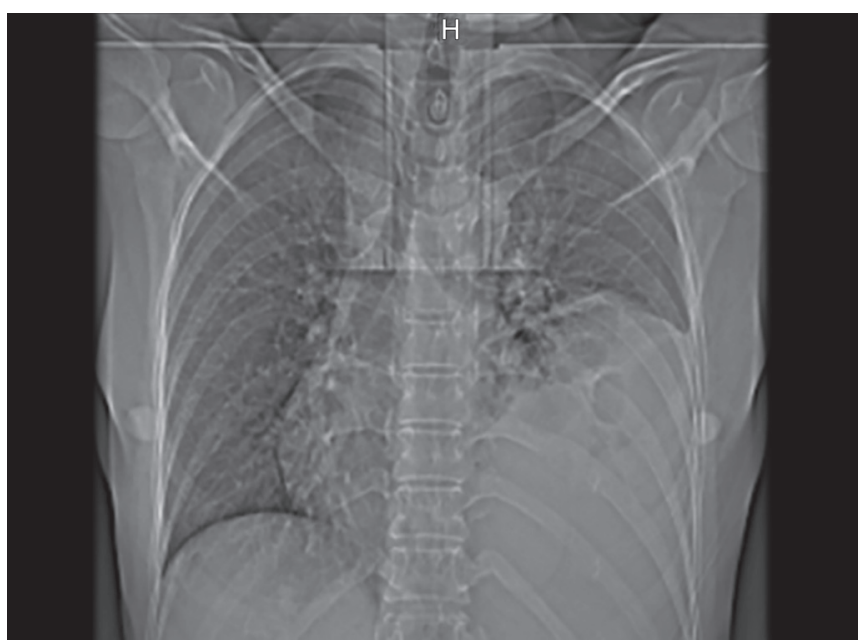

Fig. 1: Chest X-ray - Posteroanterior view

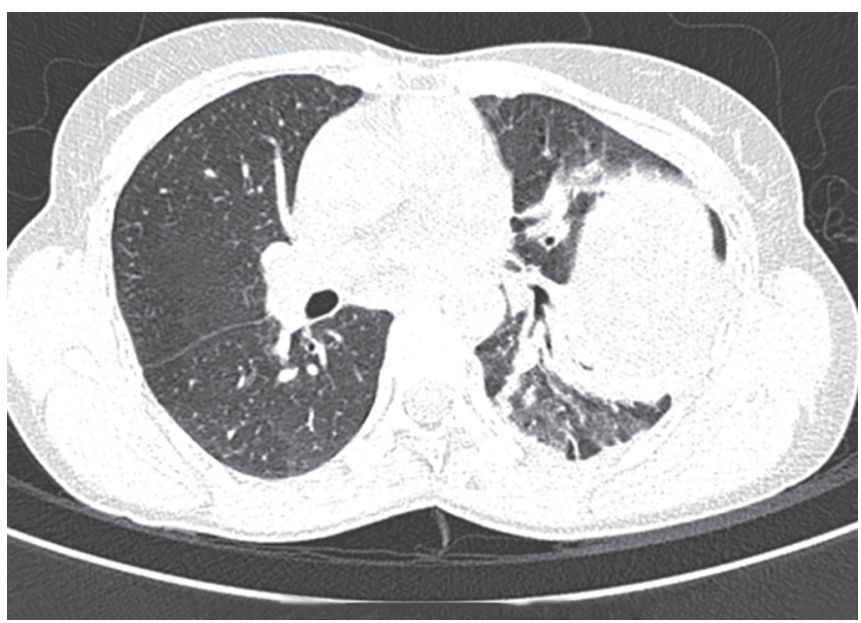

Fig. 2: Computed tomography thorax (lung window)

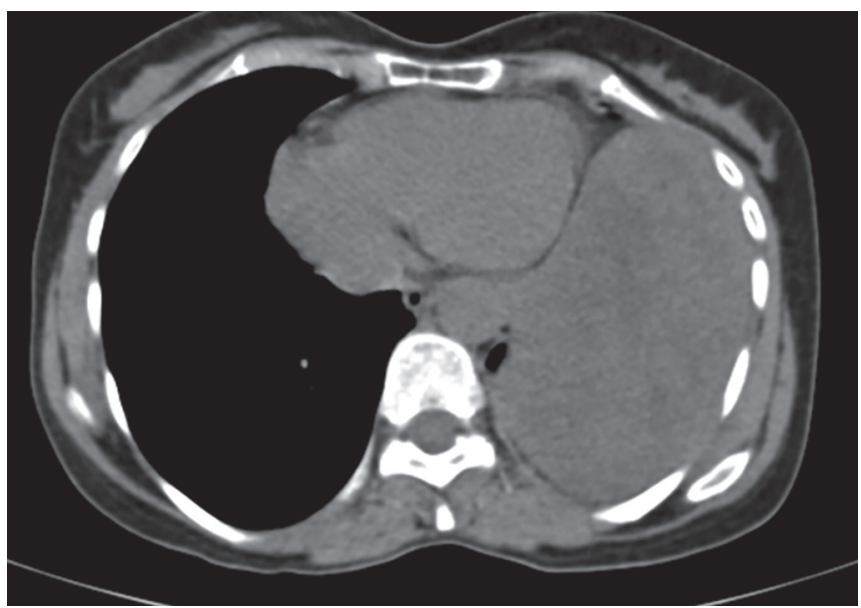

Fig. 3: Computed tomography thorax (mediastinal window) 


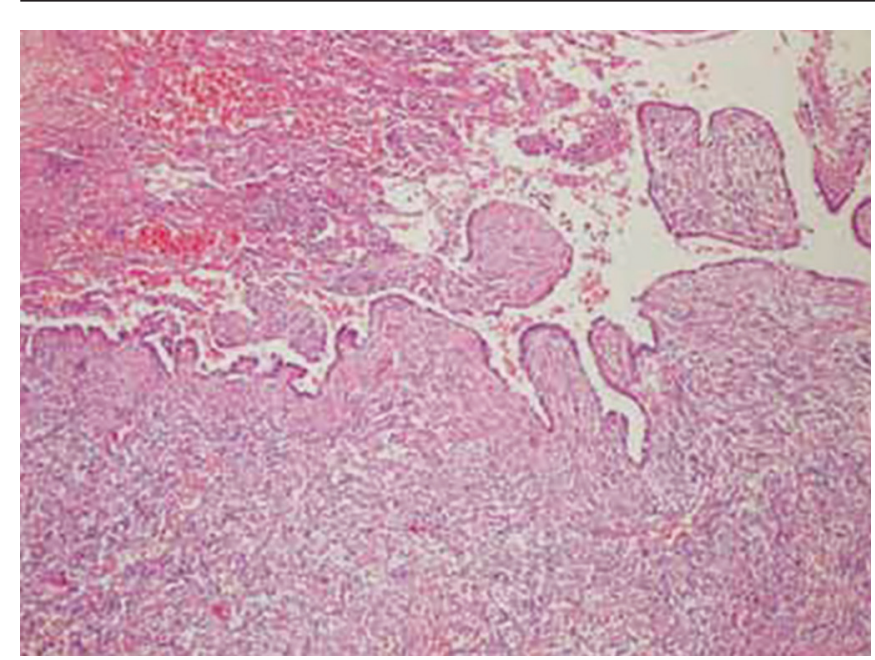

Fig. 4: Histopathological examination of left lower lobe mass lesion

transthoracic fine-needle aspiration cytology and biopsy was done from the mass lesion. Histopathology showed spindle cells arranged in fascicles with no evidence of atypia or necrosis (Fig. 4). Features were suggestive of a SFT.

\section{DISCUSSION}

Solitary fibrous tumors are rare neoplasms that are predominantly benign. They usually occur in the 5th and 6th decade of life, with no gender predilection. ${ }^{3}$ Around 10 to $30 \%$ may be malignant. The cause of the tumor remains unexplained. They most often involve the visceral pleura (two-thirds of the cases). In our case, the tumor did not show radiological or histological continuity with the visceral pleura. Histologically, the tumors are composed of spindle cells with dense bundle collagen arranged in a so-called "patternless pattern" i.e., characterized by a haphazard distribution of spindle cells and collagen fiber. ${ }^{2,3}$ Surgical excision is the treatment of choice. These tumors have a good prognosis with low rates of recurrence.

Localized fibrous tumors are submesothelial in origin based on immunohistochemical and ultrastructural findings. ${ }^{2,3}$ Most often these tumors involve the visceral pleura and are attached to the pleura by a pedicle. The cause of the tumor remains is unexplained. Most often they are classified as benign or malignant, based on histologic findings (e.g., pleomorphism, mitotic activity, invasive growth, or presence of necrosis). ${ }^{1,2}$ Immunohistochemically, the tumors have been shown to lack expression of cytoplasmic keratin and to express vimentin, a marker of mesenchymal cells. ${ }^{1-5}$ Their positive expression of CD34, a transmembrane cell-surface glycoprotein, has recently been shown by several studies, and may be useful for excluding similar spindle-cell neoplasms in differential diagnosis. ${ }^{1,6}$
Localized fibrous tumors of the pleura are exophytic pedunculated masses that extend from the visceral pleura into the thoracic cavity, and inward growth into the lung parenchyma is rare. Such tumors are then termed "inverted." In our case, the tumor did not show histologic continuity with the visceral pleura. In addition, alveolar pneumocytes and small bronchioles that retained their histologically benign appearances were entrapped within fibrous cells of the tumor. Hence, we presume this tumor to have arisen from the parenchyma of the lung. Early reports of "fibro-adenoma" of the lung may represent this spindle-cell tumor with entrapped alveolar epithelium. ${ }^{7}$ Yousem and Flynn ${ }^{4}$ suggest that this localized fibrous tumor arose not from the pleura, but rather from the lung parenchyma itself. Apart from many theories, two main hypotheses for their entirely parenchymal location have been proposed. ${ }^{4,5}$ First, the subpleural mesenchyma is in direct continuity with the connective tissue of the interlobular septa, and intrapulmonary fibromas may arise from the septal mesenchyma or invagination of the visceral pleura. Second, these tumors may originate from facultative fibroblastic elements, which can be seen in the submesothelial area of normal pulmonary parenchyma. These elements have ultrastructural and immunohistochemical features similar to those of subpleural connective tissue elements. ${ }^{8}$ Our case may be in agreement with the latter hypothesis because of entrapped small bronchioles within the tumor. Hence, with this parenchymal location of the lung, the tumor should not be pathologically mistaken for carcinosarcoma or adenocarcinoma with a metaplastic spindle-cell component.

\section{CONCLUSION}

A SFT arising from the lung parenchyma is extremely rare. Complete surgical resection is the treatment of choice. Due to the rarity of these tumors, a long-term follow-up of cases is needed to clarify their clinicopathologic behavior and rule out malignant transformation.

\section{REFERENCES}

1. Cardillo G, Facciolo F, Cavazzana AO, Capece G, Gasparri R, Martelli M. Localized (solitary) fibrous tumors of the pleura: an analysis of 55 patients. Ann Thorac Surg 2000 Dec;70(6): 1808-1812.

2. de Perrot M, Fischer S, Bründler MA, Sekine Y, Keshavjee S. Solitary fibrous tumors of the pleura. Ann Thorac Surg 2002 Jul;74(1):285-293.

3. Shields, TW.; Yeldandi, AV. Localized fibrous tumors of the pleura. In: Shields, TW.; Locicero, J III; Ponn, RB.; Rusch, VW., editors. General thoracic surgery. 6th ed. Philadelphia: Lippincott Williams and Wilkins; 2005. p. 889-900.

4. Yousem SA, Flynn SD. Intrapulmonary localized fibrous tumor. Intraparenchymal so-called localized fibrous mesothelioma. Am J Clin Pathol 1988 Mar;89(3):365-369. 
5. Aufiero TX, McGary SA, Campbell DB, Phillips PP. Intrapulmonary benign fibrous tumor of the pleura. J Thorac Cardiovasc Surg 1995 Aug;110(2):549-551.

6. van de Rijn M, Lombard CM, Rouse RV. Expression of CD34 by solitary fibrous tumors of the pleura, mediastinum, and lung. Am J Surg Pathol 1994 Aug;18(8):814-820.
7. Sironi M, Rho B, Spinelli M. Adenofibromatous pattern in a solitary fibrous tumor of the lung. Int J Surg Pathol 2005 Jan;13(1):79.

8. Bolen JW, Hammer SP, McNutt MA. Reactive and neoplastic serosal tissue. A light-microscopic, ultrastructural, and immunocytochemical study. Am J Surg Pathol 1986 Jan;10(1):34-47. 